\title{
Kompozytowe powłoki napawane plazmowo - charakterystyka i otrzymywanie
}

\section{Composite coatings deposited by the plasma transferred arc - characterization and coating formation}

\section{Streszczenie}

$\mathrm{Na}$ podstawie literatury oraz badań własnych w artykule przedstawiono stan wiedzy na temat kompozytowych powłok otrzymywanych metodą napawania plazmowego. Omówiono ogólną charakterystykę napoin kompozytowych oraz mechanizmy ich umocnienia. Przedstawiono też metody otrzymywania napoin kompozytowych z zastosowaniem łuku plazmowego.

\section{Abstract}

The state of the art of coatings deposited by the plasma transferred arc has been presented basing on the literature study and own research. The characterization and strengthening mechanisms of composite overlay formation has been presented. The methods of composite overlay production by the plasma beam have been discussed.

Dokładne sterowanie energią liniową procesu napawania umożliwia regulację szerokości i przemian strukturalnych strefy wpływu ciepła (SWC) napoiny, bez nadmiernego rozrostu ziarna oraz pęknięć podściegowych. Wydajność procesu napawania plazmowego jest duża i w zależności od konstrukcji palnika może wynieść nawet do $22 \mathrm{~kg}$ topionego proszku na $1 \mathrm{~h}[1,2]$. Można napawać przedmioty płaskie i obrotowe wykonane ze stali węglowych, stopowych i odpornych na korozję, staliwa oraz niektórych gatunków żeliw. Napawane są np. wałki rozrządu, zawory i gniazda zaworowe silników spalinowych, sworznie i czopy łożyskowe, nurniki homogenizatorów, formy do precyzyjnego kształtowania wyrobów szklanych, łopatki turbin, narzędzia skrawające, krawędzie tnące narzędzi do prac ziemnych, śruby wytłaczarek, części armatury hydraulicznej i urządzeń instalacji naftowych $[2 \div 7]$.

Ze względu na koszt urządzeń do napawania plazmowego i materiałów dodatkowych (proszków) metoda ta stosowana jest głównie do nakładania warstw o szczególnych właściwościach, tj. wysokiej twardości i odporności na zużycie ścierne. Materiał napoiny stanowią zwykle proszki na osnowie kobaltu, niklu i żelaza [2, 8, 9]. Osnowę można wznowić przez dodatek twardych cząstek, np. węglików, borków, tlenków, czy krzemianów, otrzymując w ten sposób powłoki kompozytowe.
Dr inż. Mariusz Bober - Politechnika Warszawska. 
Powłoki kompozytowe mogą być również otrzymywane technikami napawania laserowego, przetapiania wiązką elektronów bądź natryskiwania cieplnego [8, 10]. W warunkach dużego obciążenia ściernego powłoki kompozytowe przez natryskiwanie cieplne ulegają jednak szybkiej degradacji ze względu na mechaniczny charakter połączenia warstwy z materiałem podłoża oraz porowatość tych warstw. Większą trwałość wykazują warstwy napawane, w których istnieje metalurgiczny charakter połączenia powłoki z materiałem podłoża. Zastosowanie do napawania warstw kompozytowych wysokoenergetycznych wiązek, takich jak laserowa i elektronowa, może powodować rozpuszczanie twardych cząstek fazy umacniającej, co prowadzi do pogorszenia właściwości tych powłok. Z tego względu napawanie plazmowe proszkowe jest często stosowaną techniką otrzymywania powłok kompozytowych

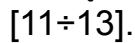

\section{Napoiny o strukturze materiału kompozytowego}

Napoiny kompozytowe o osnowie metalicznej umacnianej twardymi cząstkami, np. węglikami metali przejściowych z IVB $\div$ VIB grupy układu okresowego, łączą właściwości odpornej na ścieranie i jednocześnie stosunkowo plastycznej, a także odpornej na korozję matrycy oraz twardej ceramiki. Właściwości tego rodzaju powłok powierzchniowych sprawdzają się wszędzie tam, gdzie wymagana jest wysoka odporność na ścieranie przy równolegle występujących obciążeniach dynamicznych. Wymaganiom tym nie moga sprostać ani znane i stosowane warstwy metaliczne nakładane metodami spawalniczymi, ani warstwy ceramiczne, twarde i kruche. Takie powłoki kompozytowe nanoszone są m.in. na części silników spalinowych, odrzutowych, turbiny gazowe, zawory, śruby wytłaczarek, matryce do kucia na gorąco, zsypy piecowe itp. Dodatek twardych cząstek o różnym stopniu dyspersji powoduje dodatkowe umocnienie osnowy. Kompozyty o takiej osnowie metalowej mogą przenosić większe naprężenia rozciągające i ściskające niż stopy monolityczne, ponieważ przyłożone obciążenie jest przenoszone z plastycznej osnowy do cząstek fazy umacniającej, co jest możliwe w przypadku istnienia wiązania pomiędzy osnową a cząstkami fazy umacniającej [8]. Charakter granicy międzyfazowej pomiędzy matrycą a fazą umacniającą zależy od czasu i temperatury formowania się powłoki kompozytowej oraz od składu chemicznego osnowy. Zainteresowanie tymi materiałami wynika także $z$ ich korzystnego parametru konstrukcyjnego, jakim jest stosunek wysokiej wytrzymałości do masy.

\section{Mechanizmy umocnienia napoin kompozytowych}

W materiałach kompozytowych obecność w plastycznej osnowie cząstek o małych rozmiarach $(0,01 \div 0,1 \mu \mathrm{m})$ hamuje ruch dyslokacji, powodując ugięcie linii dyslokacji i tworzenie się pętli wokół cząstek (rys. 1). Dalszy ruch dyslokacji wymaga już przyłożenia większego naprężenia. Obserwuje się wówczas makroskopowe podwyższenie granicy plastyczności kompozytu [14].

W materiałach kompozytowych umacnianych cząstkami o wielkości powyżej $1 \mu \mathrm{m}$ nie może nastąpić utwardzenie wydzieleniowe, a materiał uzyskuje właściwości użytkowe będące wynikiem oddziaływania zarówno osnowy, jak i rozmieszczonych w niej cząstek fazy umacniającej [15].

W powłokach kompozytowych napawanych plazmowo, w zależności od konstrukcji plazmotronu, wielkość cząstek fazy umacniającej może zawierać się zasadniczo w przedziale $40 \div 250 \mu \mathrm{m}$. Jednakże najczęściej zakres ten jest węższy i wynosi 50 $\div 150 \mu \mathrm{m}$. To ograniczenie metody PPTAW sprawia, że w napoinach tych trudno jest uzyskać umocnienia wynikające z obecności cząstek dyspersyjnych. Wysokie właściwości tych powłok wynikają bowiem z dużej twardości i odporności na zużycie ścierne dużych cząstek faz umacniających rozmieszczonych w plastycznej osnowie.

Powłoki kompozytowe odznaczają się wysoką twardością, a także dużą odpornością na zużycie ścierne w warunkach pracy pod dużym obciążeniem. Ten rodzaj zużycia jest spotykany wówczas, gdy pomiędzy dwoma pracującymi częściami metalowymi znajdują się drobne i twarde cząstki, jak np. w młynach kulowych i walcowych, zębach kół zębatych, bębnach hamulcowych itp. Oszacowano, że ok. 50\% części maszyn i urządzeń ulega zużyciu ściernemu. Odporność na zużycie ścierne jest zależna od

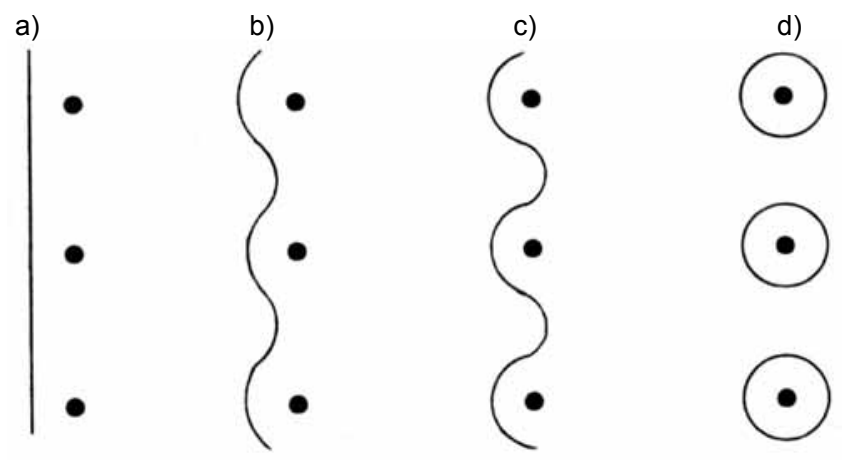

Rys. 1. Stadia przejścia dyslokacji przez obszar zawierający cząstki fazy umacniającej: a) dojście do cząstek, b) ugięcie na cząstkach, c) ominięcie cząstek, d) utworzenie pętli wokół cząstek [14]

Fig. 1. The phases of dislocation movement through the region containing reinforcing particles. Dislocation: a) approaches particles, b) diffracts on particles, c) omits particles, d) creates a loop around particles [14] 
a)

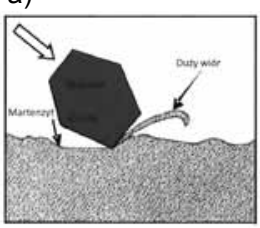

b)

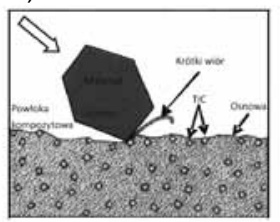

c)

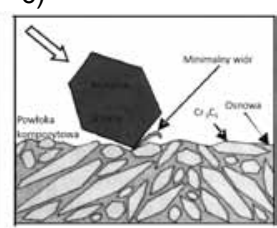

Rys. 2. Wpływ struktury warstwy wierzchniej na zużycie ścierne: a) napoina o strukturze martenzytu - średnia twardość 58 HRC, b) napoina kompozytowa umacniana małymi cząstkami TiC - średnia twardość $58 \mathrm{HRC}, \mathrm{c}$ ) napoina kompozytowa umacniana dużymi cząstkami $\mathrm{Cr}_{3} \mathrm{C}_{2}$ - średnia twardość 55 HRC [16]

Fig. 2. The effect of surface layer structure on the wear resistance: a) the overlay with martensite structure - average hardness 58 HRC, b) the composite overlay reinforced with small TiC particles - average hardness $58 \mathrm{HRC}, \mathrm{c}$ ) composite overlay reinforced with large $\mathrm{Cr}_{3} \mathrm{C}_{2}$ particles - average hardness 55 HRC [16]

twardości oraz struktury napoiny. Na rysunku 2 przedstawiono powłoki o zbliżonej twardości i różnej strukturze, poddane zużyciu ściernemu. Najwyższą odporność na zużycie ścierne wykazują powłoki kompozytowe o stosunkowo najmniejszej twardości, umacniane dużymi cząstkami węglika chromu. Twarde cząstki fazy umacniającej znacząco zapobiegają procesowi ścierania warstwy, dzięki czemu tylko nieznacznemu mikroskrawaniu ulega matryca (rys. 2c). Jednocześnie plastyczna osnowa zapobiega wykruszaniu się cząstek twardej fazy. Powłoki kompozytowe o większej twardości umacniane małymi cząstkami $w$ tych samych warunkach pracy ulegają intensywniejszemu zużyciu ściernemu (rys. 2b).

\section{Otrzymywanie napoin kompozytowych}

Powłoki kompozytowe napawane plazmowo można otrzymać, stosując różne techniki napawania. Przedstawiono je na rysunku 3.

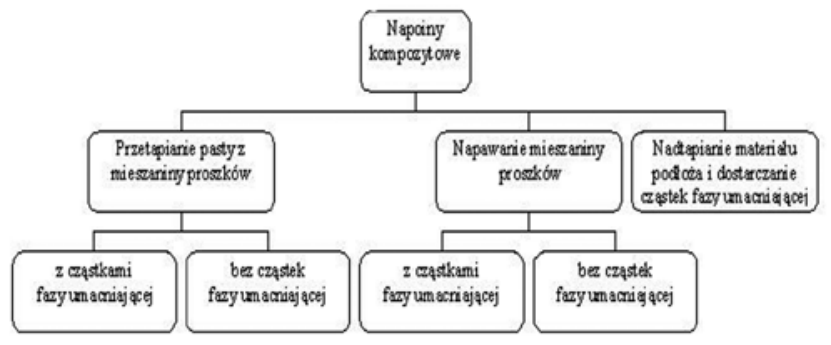

Rys. 3. Techniki napawania plazmowego powłok o strukturze kompozytowej

Fig. 3. The techniques of plasma overlaying of composite coating
Pierwsza metoda polega na nałożeniu pasty z mieszaniny proszków i jej przetopieniu łukiem plazmowym oraz warstwy powierzchniowej materiału podłoża. Do napawania stosowane są proszki o małej ziarnistości $(1 \div 40 \mu \mathrm{m})$ przygotowane $w$ formie pasty z nośnikiem alkoholowym bądź szkła wodnego, naniesionej na materiał podłoża. Stosowane są mieszaniny proszków z dodatkiem cząstek fazy umacniającej, np. TiC, które w wyniku przetopienia tworzą napoiny o strukturze kompozytowej [17]. Ciągły rozwój inżynierii powierzchni sprawia, że obecnie oprócz wysokotopliwych faz stosowane są również inne dodatki, np. siarczki $\left(\mathrm{MoS}_{2}, \mathrm{MnS}\right)$. W wyniku przetopienia pasty Fe-Mn-S uzyskano powłoki kompozytowe z cząstkami MnS charakteryzujące się zdolnościami samosmarnymi [25]. Przetapiane są, pasty z mieszaniny proszków bez dodatku twardych faz również zawierające często $\mathrm{Cr}$, Mo, W, V i C, które w wyniku obróbki dają także powłoki o strukturze kompozytowej z wydzieleniami węglików jak również borków i faz międzymetalicznych in situ [18].

Powłoki kompozytowe otrzymywane są również poprzez napawanie plazmowe $z$ mieszaniny proszków osnowy i fazy umacniającej lub w których cząstki fazy umacniającej powstają $z$ innych faz in situ. W pierwszym wariancie jako materiał dodatkowy stosowane są mieszaniny, w których osnowę stanowią proszki na bazie niklu lub kobaltu, a niekiedy żelaza z dodatkiem twardych faz, często węglików metali przejściowych $[10,19,20]$. Takie mieszanki proszków metalicznych z dodatkową fazą wzmacniającą oferowane są na rynku wyrobów spawalniczych lub są wykonywane we własnym zakresie. Technika ta umożliwia sterowanie strukturą - ilością i rozmieszczeniem fazy umacniającej - a tym samym właściwościami napoin. Uzyskane powłoki kompozytowe charakteryzują się twardością i odpornością na zużycie ścierne znacznie wyższą niż materiał podłoża. Przykłady mikrostruktur napoin otrzymanych z mieszanin proszków na osnowie Ni z dodatkiem TiC i WC przedstawiono na rysunku 4.
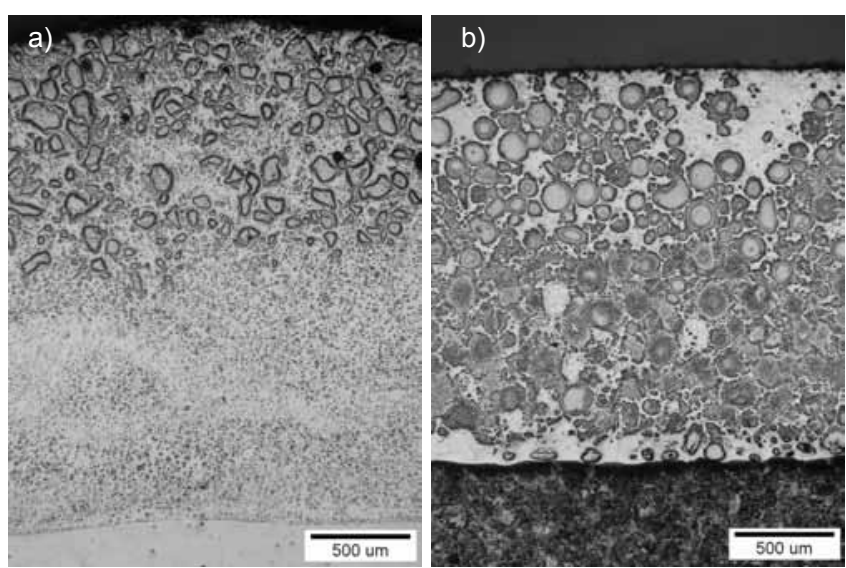

Rys. 4. Mikrostruktury kompozytowych powłok o osnowie stopu $\mathrm{Ni}$ umacnianych: a) TiC, b) WC

Fig. 4. The microstructure of $\mathrm{Ni}$ alloy based composite coatings reinforced by: a) TiC, b) WC 
W drugim wariancie, częściej stosowanym, w wyjściowej mieszaninie proszków obok głównych pierwiastków (Ni, Co, Fe) znajdują się dodatki stopowe takie jak: C, B, Si, W, Mo. Podczas napawania, w wyniku reakcji pomiędzy składnikami proszku i materiału podłoża, powstają twarde fazy rozmieszczone w meta-

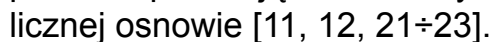

Powłoki kompozytowe można także otrzymywać w wyniku nadtopienia strumieniem plazmy modyfikowanej powierzchni materiału i dostarczenie do ciekłego jeziorka dodatku proszku fazy umacniającej. Wówczas osnowę tych powłok stanowi materiał podłoża. Warunkiem decydującym o możliwości powstawania tego rodzaju powłok kompozytowych jest konstrukcja palnika plazmowego. Wymagane jest, aby strumień wstrzykiwanych cząstek fazy umacniającej przecinał się z wiązką plazmową na powierzchni materiału podłoża [8]. Stosowane są także klasyczne plazmotrony, które topią powierzchnię metalu, a proszek fazy umacniającej podawany jest z niezależnych podajników. Technika ta jest stosowana m.in. do modyfikacji powierzchni stopów aluminium i tytanu. Do ciekłego jeziorka stopów aluminium dodawane są cząstki NbC, TiC, SiC i $\mathrm{Al}_{2} \mathrm{O}_{3}$ [8]. $\mathrm{Z}$ kolei warstwa wierzchnia tytanu może być modyfikowana przez dodatek $\mathrm{NbC}, \mathrm{TiC}, \mathrm{WC}$, $\mathrm{Cr}_{3} \mathrm{C}_{2}$ [8, 24]. Mimo że stopy tytanu i aluminium są powszechnie stosowane w budowie maszyn, to jest stosunkowo niewiele danych na temat na temat ich modyfikacji strumieniem plazmy.

Na podstawie analizy literatury, w tablicy I przedstawiono zestawienie najczęściej modyfikowanych podłoży oraz materiałów tworzących napoiny w procesie wytwarzania powłok kompozytowych strumieniem plazmy.

Badania napoin kompozytowych są oparte głównie na wnikliwej analizie mikrostruktur, badaniu odporności na zużycie ścierne w temperaturze otoczenia i podwyższonej oraz na pomiarze twardości. Wyniki wskazują na bardzo dobre właściwości powłok kompozytowych, niekiedy kilkakrotnie przewyższające analogiczne właściwości materiału podłoża. Natomiast brak jest informacji o wynikach badań podstawowych (zwilżalności, rozpływności, zachowaniu się cząstek w strumieniu plazmy) dotyczących zjawisk i procesów będących podstawą wytwarzania tego typu powłok. Dane te mogłyby być niewątpliwie pomocne w projektowaniu tego typu napoin.

Tablica. Materiał podłoża oraz materiał napoin wykorzystywany w procesie otrzymywania powłok kompozytowych metodą napawania plazmowego

Table. The substrate and overlay material used in the process of composite coatings deposited by plasma overlaying

\begin{tabular}{|c|c|c|c|c|c|}
\hline \multirow{2}{*}{ Materiał podłoża } & \multicolumn{2}{|c|}{ Materiał napoiny } & \multirow{2}{*}{$\begin{array}{l}\text { Postać materiału } \\
\text { dodatkowego }\end{array}$} & \multirow{2}{*}{ Ziarnistość, $\mu \mathrm{m}$} & \multirow{2}{*}{ Literatura } \\
\hline & osnowa & faza umacniająca & & & \\
\hline Stal niskowęglowa & Cr-Mo-C & $50 \% \mathrm{TiC}$ & pasta & $1-45$ & 17 \\
\hline Stal niskowęglowa & żelazo & $\begin{array}{c}10 \% \mathrm{MoS}_{2} \\
20 \% \mathrm{MoS}_{2} \\
30 \% \mathrm{MoS}_{2} \\
10 \%(\mathrm{Mn}+\mathrm{S})\end{array}$ & pasta & & 25 \\
\hline Stal niskowęglowa & W-Mo-Cr-V-C & & pasta & $1-40$ & 18 \\
\hline Stal nierdzewna & $\mathrm{NiTi}$ & & pasta & & 26 \\
\hline Stal niskowęglowa & stop $\mathrm{Ni}$ & $30 \% \mathrm{Cr}_{3} \mathrm{C}_{2}$ & proszek & $75-185$ & 10 \\
\hline Stal średniowęglowa & Stellite 6 & $30 \% \mathrm{Cr}_{3} \mathrm{C}_{2}$ & proszek & & 19 \\
\hline Stal nierdzewna & Stellite 6 & $\begin{array}{c}20 \% \mathrm{WC} \\
50 \% \mathrm{TiC} \\
50 \% \mathrm{Cr}_{3} \mathrm{C}_{2} \\
40 \% \mathrm{NbC}^{2}\end{array}$ & proszek & $53-180$ & 20 \\
\hline Stal nierdzewna & Triballoy 800 & $\begin{array}{c}35 \% \text { WC } \\
35 \%(\text { WC- } 12 \% \text { Cr) }\end{array}$ & proszek & $53-180$ & 20 \\
\hline Aluminium & $\mathrm{Al}-\mathrm{Ni}$ & $\begin{array}{l}\mathrm{Al}_{2} \mathrm{O}_{3} \\
\mathrm{SiC} \\
\mathrm{TiC}\end{array}$ & proszek & 70 & 27 \\
\hline Stal węglowa & Fe-Cr-C-Ni & & proszek & $70-140$ & 11 \\
\hline Stal węglowa & $\mathrm{Fe}-\mathrm{Cr}-\mathrm{C}-\mathrm{Ni}$ & & proszek & & 12 \\
\hline Stal nierdzewna & Fe-Ti-C & & proszek & $70-140$ & 13 \\
\hline Stal węglowa & stop $\mathrm{Ni}$ & & proszek & 135 & 21 \\
\hline Stal niskowęglowa & stop Co & & proszek & $75-180$ & 22 \\
\hline Stal nierdzewna & stop NiCr-B & & proszek & & 23 \\
\hline Tytan & & $\mathrm{NbC}$ & proszek & $80-120$ & 24 \\
\hline
\end{tabular}




\section{Podsumowanie}

Coraz częstsze stosowanie w przemyśle warstw kompozytowych na powierzchni detali wynika $z$ ich bardzo dobrych właściwości, w tym trybologicznych, ale i korzystnego parametru konstrukcyjnego, jakim jest stosunek wytrzymałości do masy. Napoiny kompozytowe uzyskane techniką PPTAW charakteryzują się wysoką jakością, a ich właściwości takie jak twardość i odporność na zużycie ścierne znacznie przewyższają właściwości materiału podłoża, który najczęściej stanowią stopy żelaza, jak również niklu i kobaltu oraz aluminium i tytanu. Są to na ogół powłoki umacniane węglikami metali przejściowych bądź borkami. Wysokie właściwości tych powłok wynikają z obecności cząstek twardych faz w metalicznej osnowie.

Większość publikowanych badań dotyczy napoin kompozytowych z fazami umacniającymi tworzącymi się in situ. Nieliczne opracowania są poświęcone warstwom uzyskanym z mieszaniny proszków zawierających cząstki fazy umacniającej. Stosowanie w procesie napawania materiału dodatkowego $w$ postaci mieszanin proszków osnowy i fazy umacniającej pozwala na precyzyjniejsze sterowanie strukturą powłok kompozytowych, a tym samym ich właściwościami.

Prowadzone są również badania nad innymi warstwami kompozytowymi, w tym z dodatkami $\mathrm{MoS}_{2}$ i MnS, poprawiającymi właściwości trybologiczne.

\section{Literatura}

[1] Jitai N., Wei G., Mianhuan G., Shixiong L.: Plasma application in thermal processing of materials, Vacuum 65,2002 , s. 263-266.

[2] Klimpel A.: Technologie napawania i natryskiwania cieplnego, Wyd. P. Śl., Gliwice 1999.

[3] Hard Facing by Arc Welding. Metals Handbook, vol. 6, Welding and Brazing, 8th Ed. ASM Metals Park (OH), 1979, s. 152-167.

[4] Włosiński W., Chmielewski T.: Napawanie plazmowe ochronnych warstw chromowych umocnionych wtrąceniami $\mathrm{Al}_{2} \mathrm{O}_{3}$ na podłoże ze stali 3H13, Przegląd Spawalnictwa nr 8-10, 2002, s. 122-123.

[5] Weroński A., Gardyński J.: Nakładanie powłok metodą plazmową na części samochodowe, Przegląd Spawalnictwa nr 1-2, 1996, s. 14-16.

[6] Weroński A., Pałka K.: Zwiększenie trwałości nurników homogenizatorów przez napawanie plazmowe, Przegląd Spawalnictwa nr 1-2, 1996, s. 20-22.

[7] Klimpel A., Górka J., Czupryński A.: Napawanie proszkowe PTA warstw wierzchnich suwaka zasuwy urządzeń naftowych, Przegląd Spawalnictwa nr 5-6, 2006, s. 15-19.

[8] Deuis R.L., Yellup J.M., Subramanian C.: Metal-matrix composite coatings by PTA surfacing. Composite Science \& Technology, 58, 1998, s. 299-309.

[9] Wu J. B. C., Redman J. E.: Hardfacing with Cobalt and Nickel Alloys, Welding Journal, 1994, September, s. 63-68.

[10] Huang Z., Hou Q., Wang P.: Microstructure and properties of $\mathrm{Cr}_{3} \mathrm{C}_{2}$ - modified nickel - based alloy coating deposited by plasma transferred arc process, Surface \& Coatings Technology, 2008, no. 202, s. 2993-2999.

[11] Liu Y. F., Han J. M., Li R. H., Li W. J., Xu X. Y., Wang J. H., Yang S. Z.: Microstructure and dry-sliding wear resistance of PTA cald $(\mathrm{Cr}, \mathrm{Fe})_{7} \mathrm{C}_{3} / \mathrm{Y}-\mathrm{Fe}$ ceramal composite coating, Applied Surface Science, 2006, no. 252, s. 7539-7544.

[12] Liu Y. F., Xia Z. Y., Han J. M., Zhang G. L., Yang S. Z.: Microstructure and wear behavior of $(\mathrm{Cr}, \mathrm{Fe}) 7 \mathrm{C} 3$ reinforced composite coating produced by plasma transferred arc weld-surfacing process, Surface \& Coatings Technology, 2006, no. 201, s. 863-867.

[13] Liu Y. F., Mu J. S., Xu X. Y., Yang S. Z.: Microstructure and drysliding wear properties of TiC-reinforced composite coating prepared by plasma-transferred arc weld-surfacing process, Materials Science and Engineering A, 2007, no. 458, s. 366-370.

[14] Śleziona J.: Podstawy technologii kompozytów, Wyd. P. Śl., Gliwice 1998.

[15] Dobrzański L. A.: Podstawy nauki o materiałach i metaloznawstwo, WNT, Gliwice - Warszawa 2002
[16] Zollinger O. O., Beckham J. E., Monroe C.: What to know before selecting hardfacing electrodes, Welding Journal, 1998, vol. 77 , no. 2 , s. 39-43.

[17] Bourithis L., Milonas Ath., Papadimitriou G.D.: Plasma transferred arc surface alloying of a construction steel to produce a metal matrix composite tool steel with $\mathrm{TiC}$ as reinforcing particles. Surface and Coatings Technology 165, 2003, s. 286-295.

[18] Bourithis L., Papadimitriou G. D.: Synthesizing a class M high speed steel on the surface of a plain steel using the plasma transferred arc (PTA) alloying technique: microstructure and wear properties, Materials Science and Engineering A, 2003, no. 361, s. 165-172.

[19] Aoh J. N., Jeng Y. R., Chu E. L., Wu L. T.: On the wear behavior of surface clad layers under high temperature, Wear, 1999, no. 225-229, s. 1114-1122.

[20] Kim H. J., Yoon B. H., Lee Ch. H.: Sliding wear performance in molten $\mathrm{Zn}-\mathrm{Al}$ bath of cobalt-based overlayers produced by plasmatransferred arc weld-surfacing, Wear, 2003, no. 254, s. 408-414.

[21] Hou Q. Y., He Y. Z., Zhang Q. A., Gao J. S.: Influence of molybdenum on the microstructure and wear resistance of nikckel - based alloy coating obtained by plasma transferred arc process, Materials and Design, 2007, no. 28, s. 1982-1987.

[22] Hou Q. Y., Gao J. S., Zhou F.: Microstructure and wear characteristics of cobalt-based alloy deposited by plasma transferred arc weld surfacing, Surface \& Coatings Technology, 2005. no. 194, s. 238-243.

[23] Gurumoorthy K., Kamaraj M., Prasad Rao K., Sambasiva Rao A., Venugopal S.: Microstructural aspects of plasma transferred arc surfaced $\mathrm{Ni}$-based hardfacing alloy, Materials Science and Engineering A, 2007, no. 456, s. 11-19.

[24] Hung F. Y., Yan Z. Y., Chen L. H., Lui T. S.: Microstructural characteristics of PTA-ocverlayed $\mathrm{NbC}$ on pure Ti, Surface \& Coatings Technology, 2006, no. 200, s. 6881-6887.

[25] Skarvelis P., Papadimitriou G. D.: Microstructural and tribological evaluation of potential self-lubricating coatings with $\mathrm{MoS}_{2} \mathrm{IMnS}$ additions produced by the plasma transferred arc technique, Tribology International, 2009 , no. 42, s. 1765-1770.

[26] Ozel S., Kurt B., Somunkiran I., Orhan N.: Microstructural characteristic of $\mathrm{NiTi}$ coating on stainless steel by plasma transferred arc process, Surface \& Coatings Technology, 2008, no. 202, s. 3633-3637.

[27] Deuis R.L., Subramanian C., Yellup J. M.: Abrasive wear of composite coatings in a saline sand slurry environment, Wear, 1997, no. 203-204, s. 119-128. 